\title{
Data Driven Computer Simulation to Analyse an ECG Limb Lead System Used in Connected Health Environments
}

Bond, R., Finlay, D., Guldenring, D., \& Breen, C. (2016). Data Driven Computer Simulation to Analyse an ECG Limb Lead System Used in Connected Health Environments. Methods of Information in Medicine, 55(3), 258265. https://doi.org/10.3414/ME15-01-0120

Link to publication record in Ulster University Research Portal

\section{Published in:}

Methods of Information in Medicine

Publication Status:

Published (in print/issue): 20/04/2016

DOI:

10.3414/ME15-01-0120

\section{Document Version}

Author Accepted version

\section{General rights}

Copyright for the publications made accessible via Ulster University's Research Portal is retained by the author(s) and / or other copyright owners and it is a condition of accessing these publications that users recognise and abide by the legal requirements associated with these rights.

\section{Take down policy}

The Research Portal is Ulster University's institutional repository that provides access to Ulster's research outputs. Every effort has been made to ensure that content in the Research Portal does not infringe any person's rights, or applicable UK laws. If you discover content in the Research Portal that you believe breaches copyright or violates any law, please contact pure-support@ulster.ac.uk. 
Page 1

Data Driven Computer Simulation to Analyse an ECG Limb Lead System Used in Connected Health Environments

Authors: Raymond R. Bond PhD, Dewar D. Finlay PhD, Daniel Guldenring PhD, Cathal Breen BSc

Corresponding Author: $\quad$ Dr Raymond R. Bond

Email: $\quad$ rb.bond@ulster.ac.uk

Phone: $\quad+442890368156$

Address and Affiliation

Room 16G06

School of Computing and Mathematics

University of Ulster

Jordanstown campus

Shore Road

Newtownabbey

Co. Antrim

BT37 0QB

The total number of words: approx. 5000

Words count of the abstract: 305

Figures: 6

Tables: 1 
Page 2

\section{Abstract/Summary}

Background: Recently under the Connected Health initiative, researchers and small-medium engineering companies have developed Electrocardiogram (ECG) monitoring devices that incorporate non-standard limb electrode positions, which we have named the Central Einthoven (CE) configuration. Objectives: The main objective of this study is to compare ECG signals recorded from the CE configuration with those recorded from the recommended Mason-Likar (ML) configuration. Methods: This study involved extracting two different sets of ECG limb leads from each patient to compare the difference in the signals. This was done using computer simulation that is driven by body surface potential maps. This simulator was developed to facilitate this experiment but it can also be used to test similar hypotheses. This study included, (a) 176 ECGs derived using the ML electrode positions and (b) the 176 corresponding ECGs derived using the CE electrode positions. The signals from these ECGs were compared using root mean square error (RMSE), Pearson product-moment correlation coefficient (r) and similarity coefficient (SC). We also investigated whether the CE configuration influences the calculated mean cardiac axis. The top 10 cases where the ECGs were significantly different between the two configurations were visually compared by an ECG interpreter. Results: We found that the leads aVL, III and aVF are most affected when using the CE configuration. The absolute mean difference between the QRS axes from both configurations was $28^{\circ}\left(\mathrm{SD}=37^{\circ}\right)$. In addition, we found that in $82 \%$ of the QRS axes calculated from the CE configuration was more rightward in comparison to the QRS axes derived from the ML configuration. Also, we found that there is an $18 \%$ chance that a misleading axis will be located in the inferior right quadrant when using the CE approach. Thus, the CE configuration can emulate right axis deviation. The clinician visually identified 6 out of 10 cases where the CE based ECG yielded clinical differences that could result in false positives. Conclusions: The CE configuration will not yield the same diagnostic accuracy for diagnosing pathologies that rely on current amplitude criteria. Conversely, rhythm lead II was not significantly affected, which supports the use of the CE approach for 
Page 3

assessing cardiac rhythm only. Any computerised analysis of the CE based ECG will need to take these findings into consideration.

\section{Introduction}

The number of persons aged over 60 is said to more than double by the year 2050 [1]. Hence, there will be a significant burden on healthcare services to treat the large number of elderly patients who have chronic diseases. Unless a new model for healthcare delivery is conceived, the cost for healthcare will become unprecedented. For example, the National Health Service (NHS) in the UK maybe forced into privatisation [2]. To help alleviate these risks, Connected Health $(\mathrm{CH})$ has been portrayed as a potential solution [3]. $\mathrm{CH}$ is a form of preventative medicine that empowers patients to be more proactive about their health. An important part in this model is the use of technologies to monitor the patient's vital signs. A number of vital signs including body temperature, blood pressure, respiratory rate and heart rhythm can already be monitored using these devices $[4,5]$. Nevertheless, accurate non-invasive real-time monitoring of cardiac activity outside the hospital is one of the most challenging implementations due to its complexity and intrusiveness [6]. The Electrocardiogram (ECG) is frequently used in the hospital for assessing the cardiac activity of a patient [7]. An ECG represents the electrical activity of the heart and has been used in clinical practice for over a hundred years [8]. It is the gold standard for diagnosing cardiac arrhythmias [8] and is the first tool used to assess patients with a suspected acute myocardial infarction [8]. Given its diagnostic utility and the fact that an ECG can be recorded at a low cost, it was one of the first tools considered for 24-hour ambulatory monitoring outside the hospital [9]. Ambulatory ECG monitoring devices often use four electrodes to record three to six limb leads [8]. As recommended by the American Heart Association (AHA), these four electrodes are normally anatomically positioned using the Mason-Likar (ML) configuration [10]. From the four electrodes used, three electrodes make up Einthoven's triangle whilst the remainder electrode acts as the ground. Although the ML configuration is traditionally used for ECG monitoring, researchers and small-medium enterprises have developed a number of teleheath devices that 
Page 4

position these electrodes at more proximal landmarks. An example product has been illustrated in Figure 1. It shows the extreme proximal electrode positions, which we have named the Central Einthoven (CE) configuration. The figure also illustrates how these devices can be used to stream real-time ECG data via Bluetooth and Wi-Fi to the 'Cloud' for display on a physician's portal [11]. There are a number of reasons why these devices adopt the $\mathrm{CE}$ configuration. For example, the CE configuration is less obtrusive and improves patient comfort (given the electrodes are further from the limbs). Whilst the current model of healthcare is to monitor the ill, $\mathrm{CH}$ is an emerging model that encourages even healthy citizens to record vital signs in the home, which is often referred to as disease prevention (i.e. monitoring the healthy and not just the ill). Engineering companies have seen this as an opportunity to develop a mass of inexpensive ECG monitoring devices for home-based telehealth. Thus, there could be a larger movement towards citizens adopting these devices and this study shows how the CE configuration changes the morphology of the signals and the cardiac axis when compared to the recommended ML configuration.

This study sets out to compare signals recorded using the ML configuration with signals recorded using the $\mathrm{CE}$ configuration. Others have referred to the $\mathrm{CE}$ configuration as the 3electrode system [12]. Both configurations have been illustrated in Figure 2. 
Page 5

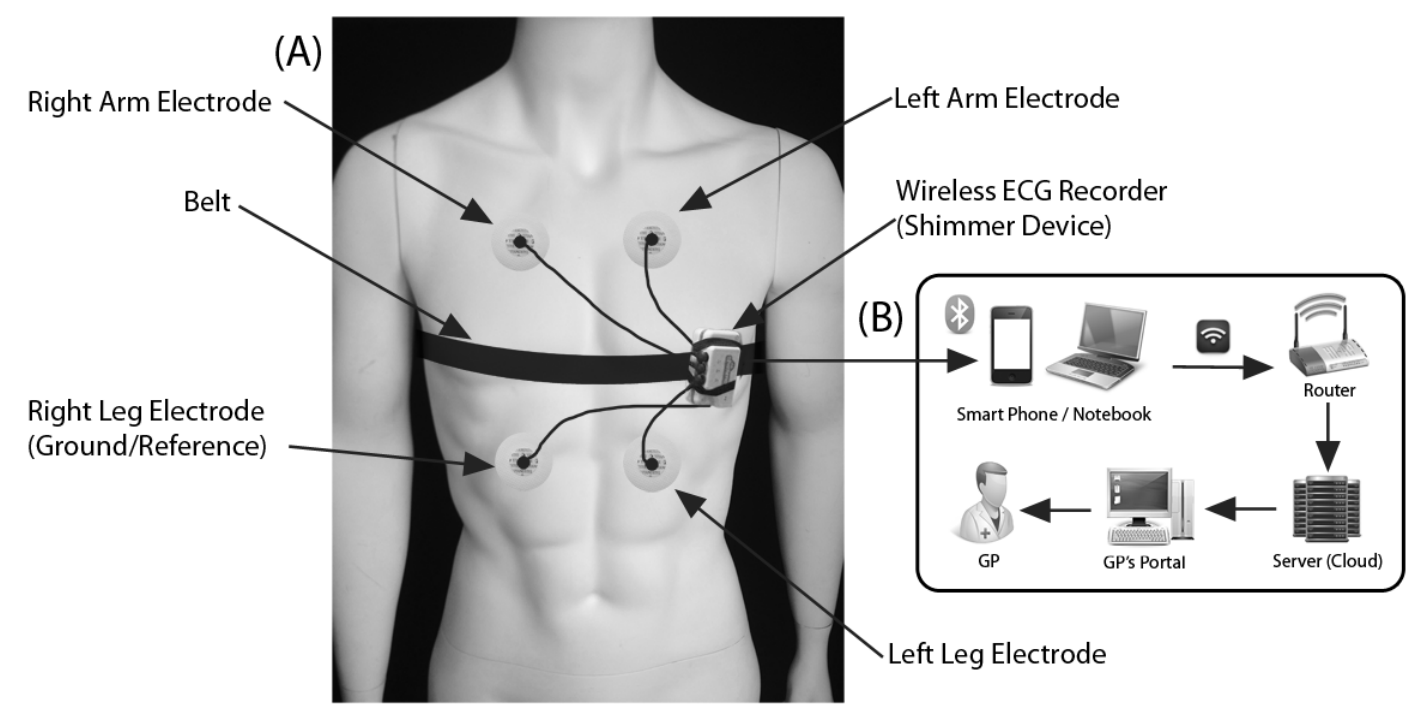

Figure 1. (A) A wireless ECG system (Shimmer device [13]) that employs the CE configuration, and (B) shows how the wireless ECG recorder can use Bluetooth and WiFi to stream data to the Cloud for display on a GP's portal.

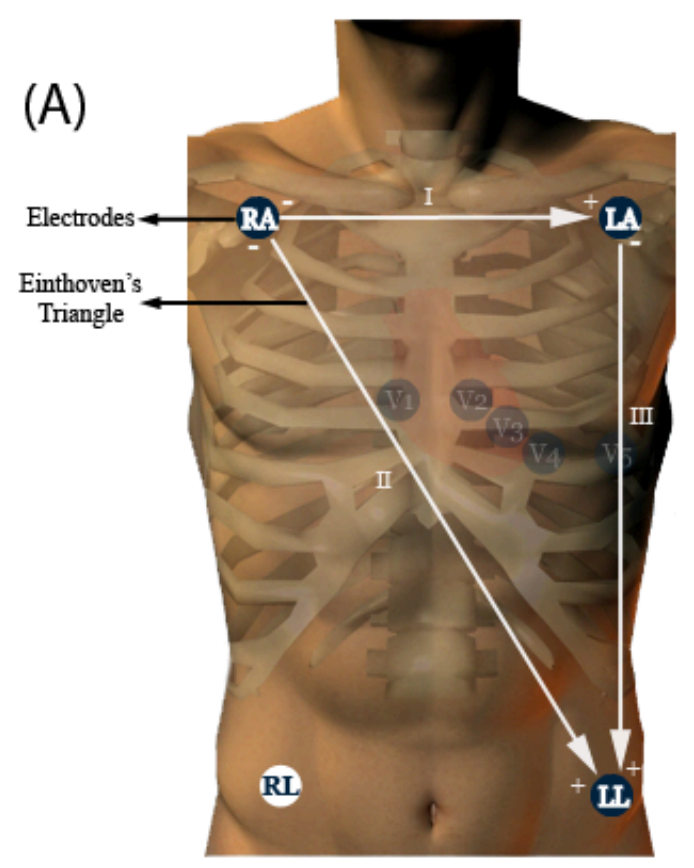

Figure 2. (A) ML configuration [14] and (B) the CE (or 'Central Einthoven') configuration where the electrodes are placed around the centre of the precordium. The figure also illustrates Einthoven's triangle where the Right Arm (RA), Left Arm (LA) 
Page 6

and Left Leg (LL) electrodes make up the recording of three Einthoven limb leads (I, II, II) and the three augmented lead (aVR, aVL, and aVF).

\section{Methods}

This is a retrospective study that involves data from 176 Body Surface Potential Maps (BSPMs) that were recorded from healthy subjects who had no ECG abnormalities. It is imperative to analyse the effects of the CE configuration on healthy subjects for a number of reasons, (a) $\mathrm{CH}$ devices will be used by a healthy population for the purposes of the early detection of disease (also known as disease prevention) and (b) to determine the potential of false positives.

The BSPMs (each having 192 leads) were collected by the cardiology faculty of the Nora Eccles Harrison Cardiovascular Research and Training Institute at the University of Utah. Subjects and patients were consented using University of Utah procedures that were approved by the Institutional Review Board (IRB). This approval was granted and in place at the time of the recordings.

A BSPM is a specialised ECG recording that uses a large number of electrodes positioned around the entire torso [15]. Each BSPM used in this study was recorded using 192 electrodes [16]). Given a BSPM contains almost all of the electrocardiographic information that is available on the body surface, we extracted two different ECG subsets from each BSPM. This included subset (a) a 6-lead ECG derived from the ML configuration (Figure 2a), and subset (b) a 6-lead ECG derived using the CE configuration (Figure 2b). In total, we extracted 352 ECGs from the entire dataset (176 ML 6-lead ECGs and 176 CE 6-lead ECGs). The actual extraction process was carried out using our Electrode Misplacement Simulator (EMS) which was developed at the University of Ulster [17]. Using BSPM datasets is an optimal scientific approach for comparing different ECG subsets for a number of reasons. The primary reason is that a BSPM is comprised of hundreds of ECG leads that are recorded from all parts of the 
Page 7

torso and importantly, these leads are recorded at the same 'time period'. As such we opted to utilize BSPMs for our comparative study given BSPM data facilitates 'like-for-like' comparisons due to the fact that the ECG signals are recorded simultaneously. Thus, using BSPM data for these type of studies has become a standard approach in the research community $[18,19]$.

As described in the following section, linear interpolation was performed to extract some of the ECG leads from the BSPM. Any interpolated leads were calculated from BSPM leads that were in close proximity $(3 \mathrm{~cm}$ apart), thus derivations are very accurate and likely to have an insignificant error. Also, this approach of near field linear interpolation amongst BSPM leads has previously been shown to be accurate. According to Schijvenaars et al. [20] interelectrode interpolations based on BSPMs yield extremely small errors that are no greater than signal noise often found in chest electrodes.

\section{Electrode misplacement simulator or EMS}

The EMS was developed by the authors and has been described elsewhere [17, 21, 22]. For this study, the authors enhanced the EMS software to allow the user to alter limb electrode locations and extract the relevant leads. This new version of the EMS is available on the Internet [23]. The EMS uses an algorithm to extract any limb lead variant from a BSPM. When the user interactively moves a limb electrode, the algorithm detects the nearest four BSPM leads using Euclidean distance and the signals are derived using linear interpolation as defined in Equation 1. 
Page 8

Equation 1.

$$
\operatorname{derivedPotentials}_{(t)}=\sum_{i=1}^{n} \text { neighbourLead }_{(i, t)} \cdot \operatorname{ratio}_{(i)}
$$

where $n$ is the number of neighbour leads $(n=4)$. Each potential at time $t$ is calculated by a summation of each of the neighbour leads multiplied by a weighted ratio. The ratio is weighted for each individual neighbour lead relative to its distance from the user-defined electrode. More details can be found in previous papers [17, 21, 22].

\section{Metrics for signal analysis}

Three metrics were used in this study to quantify the similarity/difference between leads derived from the ML and CE configurations. This comparison was performed over three different intervals in the ECG, i.e. the PQRST, QRS and STT intervals. Similarity metrics include the root mean square error (RMSE), Pearson product moment correlation coefficient (r) and the similarity coefficient (SC). Mean \pm SD of the metrics were calculated using all of the data including any outliers, however outliers were removed from the boxplots to improve their readability and scale. SC is described in Equation 2.

Equation 2.

$S C=1-\frac{\sqrt{\frac{\sum_{i=1}^{n}\left(x_{i}-y_{i}\right)^{2}}{n}}}{\sqrt{\frac{\sum_{i=1}^{n} x_{i}^{2}}{n}}}$

where the denominator is the RMSE and the divisor is the Root Mean Square (RMS) of a ML lead. Within the divisor, $x_{i}$ represents a sample value from a ML lead. 
Page 9

\section{Mean frontal QRS electrical axis}

We also compared the difference in the QRS axes as calculated from the ML and CE configurations. The QRS axis is not normally used in remote monitoring cases but it can be used to indicate structural and conduction abnormalities of the heart and other researchers have considered the QRS axis to be somewhat important within ECG monitoring [24, 25]. For each of the ML and CE configurations, the QRS axis was calculated using the orthogonal leads I and aVF [26] (known as the quadrant method). The calculation of the QRS axis does consider time as it is calculated using the $\mathrm{R}$ peak and $\mathrm{S}$ nadir of two leads (and since the $\mathrm{R}$ peak and S nadir can occur at slightly different times in different leads). This method of calculating the QRS axis has been defined in Equation 3.

Equation 3.

qrsAxis $=\operatorname{arcTan}\left(\frac{\text { avfRPeak }-\mid \text { avfSNadir } \mid}{\text { iRPeak }-\mid \text { iSNadir } \mid}\right)$

Where the numerator is calculated by subtracting the R peak (avfRPeak) in lead aVF from the magnitude of the $\mathrm{S}$ nadir (avfSNadir) also in lead aVF. Similarly, the denominator is calculated by subtracting the R peak (iRPeak) from the magnitude of the S nadir (|iSNadir $\mid)$ in lead I. After calculating the QRS axis for each of the ECGs, we compared the difference in QRS axis angles between the two configurations. This was done by calculating the mean absolute axis difference as defined in Equation 4

Equation 4.

meanAbsAxisDifference $=\frac{1}{n} \cdot \sum_{i=1}^{n} f\left(x_{i}, y_{i}\right)$ 
Page 10

where meanAbsAxisDifference is the absolute mean average of the values returned by the function $f\left(x_{i}, y_{i}\right) . n$ is the number of corresponding ECGs $(n=176) . x_{i}$ is the QRS axis calculated from a ML based ECG and $y_{i}$ is the corresponding QRS Axis calculated from the CE based ECG. The function is defined in Equation 5.

Equation 5.

$f(x, y)=\left\{\begin{aligned} 360^{\circ}-(|x-y|), & |x-y|>180^{\circ} \\ |x-y|, & |x-y| \leq 180^{\circ}\end{aligned}\right.$

where $f(x, y)$ returns the absolute difference between two QRS axes when the difference is less than or equal to 180 degrees. Otherwise the function returns the result of 360 degrees subtracted by the absolute difference. This ensures that the difference between two QRS axes is within a $0-180$ degrees interval (irrespective of clockwise). We then categorised each of the QRS axis using the function defined in Equation 6.

Equation 6.

$$
f(x)=\left\{\begin{aligned}
& \text { 'Normal }^{\prime}, x \geq-30^{\circ} \wedge x \leq 90^{\circ} \\
& \text { 'Inferior Right', } x>90^{\circ} \wedge x \leq 180^{\circ} \\
& \text { 'Superior Right', } x>-180^{\circ} \wedge x<-90^{\circ} \\
& \text { 'Superior Left', } x \geq-90^{\circ} \wedge x<-30^{\circ}
\end{aligned}\right.
$$

where $x$ is a QRS axis angle which is used by the function to determine the quadrant. For example, if the angle lies within $-30^{\circ}$ and $90^{\circ}$, the axis is determined 'Normal' [8]. This function was used in this study to investigate whether the CE configuration affects the quadrant classification, which is used as criteria in clinical practice. 


\section{Clinical observation}

An expert in ECG interpretation (senior clinical physiologist) was recruited to serially compare 20 ECGs (10 ECGs derived using the ML configuration against the 10 corresponding ECGs derived using the CE configuration). These 10 cases were analysed because they were most affected by the CE configuration. These cases were identified using Equation 7, which calculates a standard composite score for each set of ECGs being compared. Serial comparison also removes the effect of intra-observer variability.

Equation 7.

$$
\text { compositeScore }=\frac{1}{n} \cdot \sum_{i=1}^{n} \frac{x_{i}-y_{i}}{z_{i}}+\frac{a_{i}-b_{i}}{c_{i}} \cdot-1
$$

Where $n$ is the number of leads $(n=6), x_{i}$ corresponds to the RMSE between the ML and the corresponding CL lead $i$ (as calculated over the PQRST), $y_{i}$ is the mean RMSE of lead $i$ as calculated over all subjects in the study population and $z_{i}$ is the standard deviation of the RMSE values associated with lead $i$ as calculated over all subjects in the study population. This part of the equation calculates a standard z-value, which is used to standardise a number so that it becomes 'metric agnostic' (i.e. z-values then can be summed with z-values derived from other metrics). In this study, z-values derived from the RMSE values were summed with $\mathrm{z}$-values derived from the $r$ metric. Therefore, $a$ represents $r$ of a particular lead, $b$ is the mean $r$ of this lead (over all cases) and $c$ is the standard deviation of $r$ in this lead (over all cases). This particular z-value is inverted (as its multiplied by -1). The reason being is that high $r$ values signify that the lead is more correlated in both the $\mathrm{ML}$ and $\mathrm{CE}$ configurations (whereas high RMSE values [or their associated z-values] signify that the leads are more different). Nevertheless, these two z-values are summed to create a composite score. This is then calculated for all leads, which are averaged to create a mean composite score for each case. These scores are then used to rank each case in descending order. Hence, the top ten scoring cases were used to identify which ECGs (according to signal difference) are most affected by 
Page 12

the CE configuration. These 20 ECGs were serially compared by an ECG human interpreter (who was blinded to which ECGs were ML or CE based to avoid bias). The ECG observer was requested to consider, a) whether the differences between the two contrasting ECGs are of clinical significance/relevance, and b) rate out of 10 the similarity between the two contrasting ECGs (where 1=very different and 10=very similar).

\section{Results}

Figure 3 depicts box plots of the RMSE calculated over the PQRST, QRS and STT intervals respectively. Each box plot excludes outliers that exceeded a threshold (outliers $>=\mathrm{IQR}^{*} 1.5$ ). Figure 3a shows the RMSE values calculated over the PQRST between the six ECG leads of the ML and the CE configurations. Leads III (median RMSE $=132 \mathrm{uV}$ ), aVF (median RMSE $=118 \mathrm{uV})$ and II $($ median RMSE $=112 \mathrm{uV})$ are the most disparate leads when comparing the ML and CE configurations. For reference and to aid the interpretation of these results, the normal amplitude values and limits for the intervals in an ECG complex are as follows: P amplitude $=150 \mathrm{uV} \pm 50, \mathrm{QRS}$ height $=1500 \mathrm{uV} \pm 500, \mathrm{ST}=0 \mathrm{uV} \pm 100$ and $\mathrm{T}$ height $=300 \mathrm{uV} \pm 200$ [27].

Figure $3 \mathrm{~b}$ shows that the RMSE of the QRS is the highest in leads III (median RMSE = 289uV), aVF $($ median RMSE $=249 \mathrm{uV})$ and II $($ median RMSE $=230 \mathrm{uV})$. Figure $3 \mathrm{c}$ shows that the RMSE of the STT interval is again the highest in leads III (median RMSE $=82 \mathrm{uV}$ ) $\mathrm{aVF}($ median RMSE $=70 \mathrm{uV})$ and II $($ median RMSE $=70 \mathrm{uV})$. 
(A)

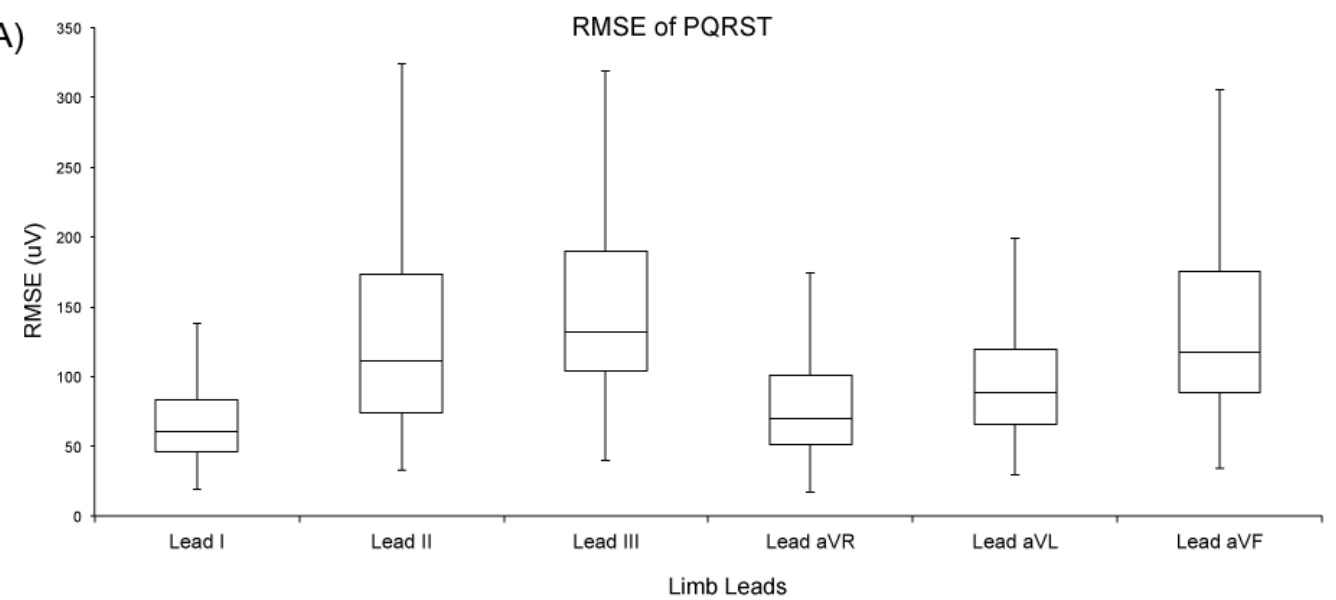

(B)

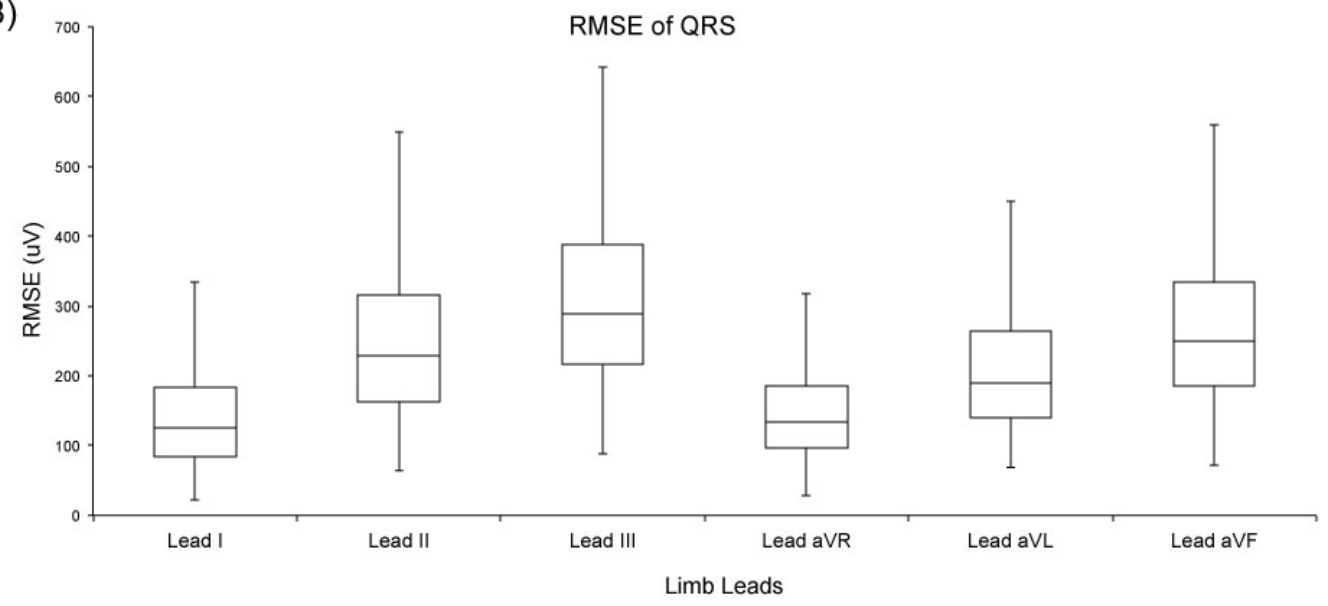

(C)

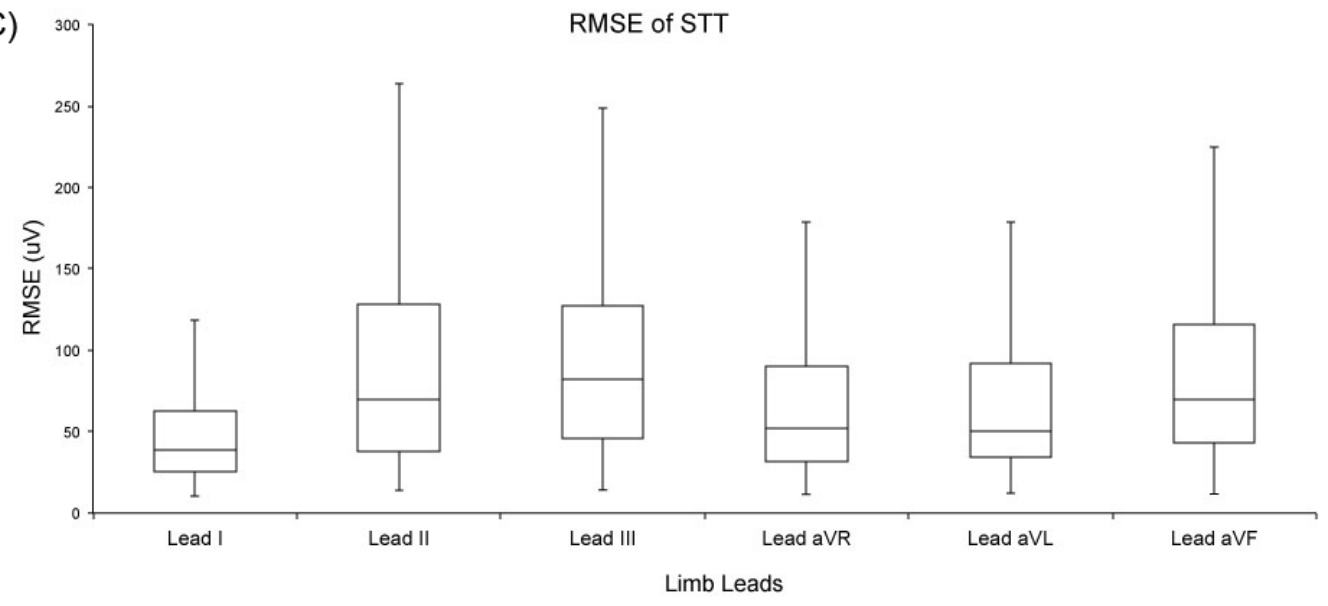

Figure 3. (A) RMSE of the PQRST across six ECG leads. (\# of upper outliers: $I=13$, $\mathrm{II}=5, \mathrm{III}=4, \mathrm{aVR}=5, \mathrm{aVL}=4$ and $\mathrm{aVF}=5$.). (B) RMSE of the $\mathrm{QRS}$ complex across six $\mathrm{ECG}$ leads. (\# of upper outliers: $I=10, I I=9, I I I=7, a V R=10$, aVL $=2$ and $\mathrm{aVF}=8$.). (C) RMSE of the STT interval across six ECG leads. (\# of upper outliers: $I=8, I I=11, I I I=15$, $a V R=7, a V L=2$ and $\mathbf{a V F}=21$.) 
Page 14

Figures 3 indicates that lead III is the most contrasting lead. However when analysing the Pearson product moment correlation coefficient, lead aVL is found to correlate the least. This can be seen in Figure 4 in which the mean similarity metrics (i.e. RMSE, r and SC) are reported for the PQRST, QRS and STT intervals. According to $r$ of the PQRST, leads aVL, III and I are the least correlated leads. In addition, according to the mean SC of the PQRST, leads aVL, III and aVF are the least similar. However, when considering all three metrics (Figure 4) it is leads aVL, III and aVF that are the most contrasting leads when comparing the two configurations.

\begin{tabular}{|c|c|c|c|c|c|c|}
\hline \multirow[b]{2}{*}{ PORST } & \multicolumn{4}{|c|}{ Least affected leads } & \multicolumn{2}{|c|}{ Most affected leads } \\
\hline & & & & & & \\
\hline RMSE & $\begin{array}{c}I \\
(70, S D=39)\end{array}$ & $\begin{array}{c}\text { aVR } \\
(81, S D=44)\end{array}$ & $\begin{array}{c}\text { aVL } \\
(98, S D=42)\end{array}$ & $\begin{array}{c}\text { II } \\
(135, \mathrm{SD}=82)\end{array}$ & $\begin{array}{c}\text { aVF } \\
(139, S D=76)\end{array}$ & $\begin{array}{c}\text { III } \\
(153, \mathrm{SD}=73)\end{array}$ \\
\hline RNASE $(\mu$ & $\begin{array}{c}\text { II } \\
(0.91, \mathrm{SD}=0.12)\end{array}$ & $\begin{array}{c}\text { aVR } \\
(0.91, \mathrm{SD}=0.12)\end{array}$ & $\begin{array}{c}\mathrm{aVF} \\
(0.89, \mathrm{SD}=0.13)\end{array}$ & $\begin{array}{c}\mathrm{I} \\
(0.82, \mathrm{SD}=0.16)\end{array}$ & $\begin{array}{c}\text { III } \\
(0.82, \mathrm{SD}=0.21)\end{array}$ & $\begin{array}{c}\mathrm{aVL} \\
(0.64, \mathrm{SD}=0.33)\end{array}$ \\
\hline & $\begin{array}{c}\text { aVR } \\
(0.53, \mathrm{SD}=0.24)\end{array}$ & $\begin{array}{c}\text { II } \\
(0.45, \mathrm{SD}=0.29)\end{array}$ & $\begin{array}{c}I \\
(0.38, \mathrm{SD}=0.31)\end{array}$ & $\begin{array}{c}\text { aVF } \\
(0.27, \mathrm{SD}=0.35)\end{array}$ & $\begin{array}{c}\text { III } \\
(-0.05, \mathrm{SD}=0.57)\end{array}$ & $\begin{array}{c}\mathrm{aVL} \\
(-0.42, \mathrm{SD}=0.79)\end{array}$ \\
\hline \multicolumn{7}{|l|}{ QRS } \\
\hline \multirow{3}{*}{$\operatorname{RMSE}(\mu \mathrm{V})$} & $\begin{array}{c}I \\
(148, \text { SD }=89)\end{array}$ & $\begin{array}{c}\text { aVR } \\
(156, S D=95)\end{array}$ & $\begin{array}{c}\text { aVL } \\
(209, \mathrm{SD}=96)\end{array}$ & $\begin{array}{c}\text { II } \\
(268, \mathrm{SD}=168)\end{array}$ & $\begin{array}{c}\text { aVF } \\
(285, \text { SD }=157)\end{array}$ & $\begin{array}{c}\text { III } \\
(319, \mathrm{SD}=156)\end{array}$ \\
\hline & $\begin{array}{c}\text { II } \\
(0.92, \mathrm{SD}=0.15)\end{array}$ & $\begin{array}{c}\text { aVR } \\
(0.91, \mathrm{SD}=0.15)\end{array}$ & $\begin{array}{c}\text { aVF } \\
(0.91, \mathrm{SD}=0.16)\end{array}$ & $\begin{array}{c}\text { III } \\
(0.84, \mathrm{SD}=0.24)\end{array}$ & $\begin{array}{c}\mathrm{I} \\
(0.75, \mathrm{SD}=0.30)\end{array}$ & $\begin{array}{c}\text { aVL } \\
(0.63, \mathrm{SD}=0.40)\end{array}$ \\
\hline & $\begin{array}{c}\text { aVR } \\
(0.55, \mathrm{SD}=0.26)\end{array}$ & $\begin{array}{c}\text { II } \\
(0.46, \mathrm{SD}=0.29)\end{array}$ & $\begin{array}{c}I \\
(0.28, \mathrm{SD}=0.43)\end{array}$ & $\begin{array}{c}\mathrm{aVF} \\
(0.28, \mathrm{SD}=0.39)\end{array}$ & $\begin{array}{c}\text { III } \\
(-0.06, \mathrm{SD}=0.70)\end{array}$ & $\begin{array}{c}\mathrm{aVL} \\
(-0.49, \mathrm{SD}=1.09)\end{array}$ \\
\hline \multicolumn{7}{|l|}{ STT } \\
\hline \multirow{5}{*}{$\operatorname{RMSE}(\mu \mathrm{V})$} & $\begin{array}{c}\mathrm{I} \\
(49, \mathrm{SD}=35)\end{array}$ & $\begin{array}{c}\text { aVL } \\
(65, \mathrm{SD}=44)\end{array}$ & $\begin{array}{c}\text { aVR } \\
(66, \mathrm{SD}=45)\end{array}$ & $\begin{array}{c}\text { aVF } \\
(99, \mathrm{SD}=85)\end{array}$ & $\begin{array}{c}\text { II } \\
(101, \mathrm{SD}=88)\end{array}$ & $\begin{array}{c}\text { III } \\
(104, \mathrm{SD}=83)\end{array}$ \\
\hline & $\begin{array}{c}\text { aVR } \\
(0.96, \mathrm{SD}=0.07)\end{array}$ & $\begin{array}{c}\text { II } \\
(0.96, \mathrm{SD}=0.05)\end{array}$ & $\begin{array}{c}\text { I } \\
(0.91, \mathrm{SD}=0.15)\end{array}$ & $\begin{array}{c}\text { aVF } \\
(0.91, S D=0.16)\end{array}$ & $\begin{array}{c}\text { III } \\
(0.78, \mathrm{SD}=0.29)\end{array}$ & $\begin{array}{c}\mathrm{aVL} \\
(0.58, \mathrm{SD}=0.43)\end{array}$ \\
\hline & $\begin{array}{c}\text { aVR } \\
(0.47, \mathrm{SD}=0.40)\end{array}$ & $\begin{array}{c}\mathrm{I} \\
(0.46, \mathrm{SD}=0.41)\end{array}$ & $\begin{array}{c}\text { II } \\
(0.38, \mathrm{SD}=0.54)\end{array}$ & $\begin{array}{c}\text { aVF } \\
(0.12, S D=0.77)\end{array}$ & $\begin{array}{c}\text { III } \\
(-0.39, \mathrm{SD}=1.17)\end{array}$ & $\begin{array}{c}\text { aVL } \\
(-0.85, \mathrm{SD}=1.56)\end{array}$ \\
\hline & & & & & \multicolumn{2}{|c|}{ Colour key } \\
\hline & & & & & & \begin{tabular}{l|l} 
I & aVR \\
II & aVL \\
III & aVF
\end{tabular} \\
\hline
\end{tabular}

Figure 4. Summary of the results used to compare six leads recorded from two different configurations (ML and CE). The figure has three sections to show the differences in three signal intervals (PQRST, QRS and STT). Each section shows the results according to three different metrics (RMSE, $r$ and SC). Each row is sequentially ordered to show the most affected lead on the right to the least affected lead on the left. The most affected lead is the lead that is the most 'different' when comparing this lead recorded from each 
Page 15

configuration. To improve its readability, each of the six ECG leads has been colour coded. This allows the reader to see the pattern of which intervals and leads contrast the least and the most.

As seen in Figure 5, we found a large difference in the QRS axes that were derived using the two different configurations. The $\mathrm{CE}$ configuration was found on average to affect the calculated QRS axis by $28^{\circ}\left(\mathrm{SD}=37^{\circ}\right)$. We also found that in $82 \%(144 / 176)$ of the QRS axes calculated from the $\mathrm{CE}$ configuration was more rightward. In addition, when analysing the quadrant of each QRS axis, we discovered that 26\% (46/176) of the QRS axes as calculated from the CE configuration lay within a different quadrant when compared to the corresponding QRS axes derived from the ML approach. As shown in Table 1, when using the CE configuration there is an $18 \%$ chance that the calculated QRS axis will misleadingly lie within the inferior right quadrant when the QRS axis should be 'normal'. Thus, we found a weak correlation $(r=0.26)$ between the QRS axes calculated from the ML and CE configurations. These results strongly indicate that the CE configuration does not facilitate reliable measurement of the QRS axis.

Table 1. Shows the chance of changing quadrant of the QRS axis if the ECG is recorded using the $\mathrm{CE}$ configuration.

\begin{tabular}{ll}
\hline Quadrant & Chance \\
\hline Inferior right & $18 \%$ \\
Superior left & $4 \%$ \\
Superior right & $2 \%$ \\
Inferior left (Normal) & $2 \%$ accounts for slightly abnormal axis that has become \\
& normal due to the CE configuration.
\end{tabular}


Page 16

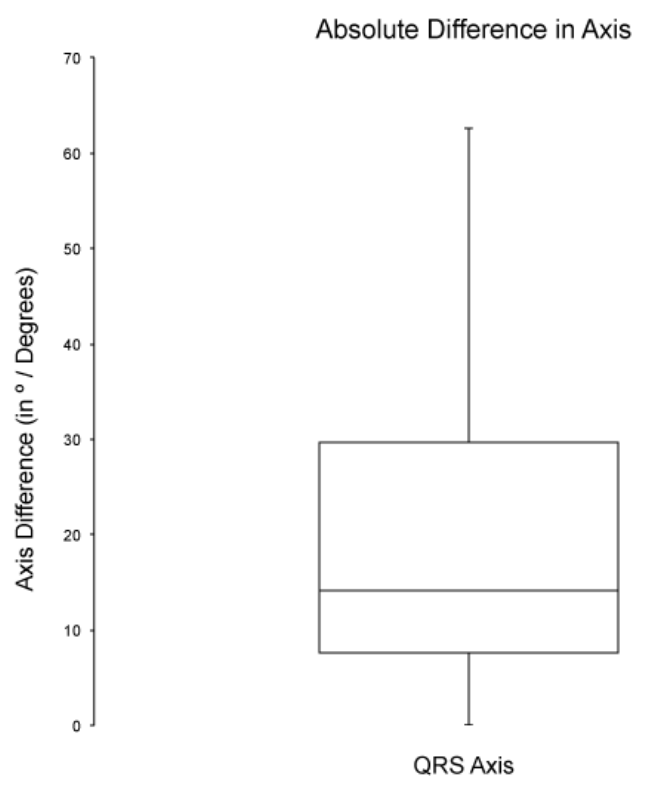

Figure 5. Box-plot of the absolute differences in QRS axis between the two configurations. (\# of upper outliers = 18)

\section{Preliminary clinical observations}

Appendix 1 indicates the cases associated with the greatest composite scores. These 10 cases have been made available online [28]. The table indicates whether the clinician identified the ECGs in each case as having clinically relevant differences. The table also indicates the similarity rating given for each case $(1=$ very different, $10=$ very similar $)$ With the mean similarity rating being $4.6(\mathrm{SD}=2.50)$ and the majority of ratings being between 1 and 4 , this indicates that the CE configuration does affect the ECG signals from a clinical perspective. In addition, the clinician identified 6 out of 10 cases where the CE based ECG yielded different features that had clinical significance when compared to the usual ML configuration. There is a moderate correlation between the composite score and the similarity rating $(r=-0.46)$ which validates the composite score. The table also showcases the detailed observations that were made during serial comparison. Recurring features involved more equiphasic leads in the $\mathrm{CE}$ based ECG (R and S wave being the same length). The CE based ECG often amplified the signal (which was also verified in the quantitative analysis). As described in the table, the $\mathrm{CE}$ 
approach can yield larger ST amplitudes. Perhaps this is due to the CE configuration accentuating early repolarisation.

\section{Discussion}

Figure 6 is an example case that shows the six limb leads recorded using the ML configuration alongside the corresponding leads recorded from the CE configuration. The figure shows a slight rightward change in the QRS axis when using the CE configuration. Although the difference is subtle in this case, right axis deviation (RAD) can allude to left posterior fascicular block or right ventricular hypertrophy [8]. Arguably, these pathologies are not generally monitored using telehealth devices and the shift in QRS axis may become well accepted. However, clinicians have considered the QRS axis in monitoring situations [24, 25].

Figure 6 demonstrates that leads aVL, III and aVF are the most contrasting leads when comparing the configurations. Lead aVL is largely affected when using the CE configuration. As shown in Einthoven's triangle (Figure 2a), the positive pole in this lead is derived from the LA electrode. And given the majority of the heart lies on the left side of the chest, the potentials recorded using the LA electrode are significantly different when it is moved from the left infraclavicular fossa to the left side of the chest. Even a small positional change in an electrode that is close to the heart can significantly alter the signal. Conversely, a small positional change on an electrode that is not close to the heart may only result in a small change to the signal $[29,30]$. This rationale may help explain why lead aVR is less affected by the CE configuration when compared to lead aVL.

The next most affected signal by the CE configuration is lead III. Using the same rationale, this could be due to the fact that lead III is derived using the LA and LL electrodes. These electrodes are in closer proximity to the heart when compared to the RA electrode. And when these electrodes are repositioned closer to the heart, lead III is significantly affected, especially regarding its amplitude. There may also be a similar explanation as to why lead 
Page 18

aVF is considerably different when using the CE configuration. The positive pole in lead aVF is provided by the LL electrode and when this electrode is positioned significantly closer to the heart, thus the amplitude of lead aVF is significantly enhanced.

Although the aforementioned leads exhibit substantial morphological differences in the two configurations, lead II is almost identical. This can be seen in the example provided in Figure 6 and in the metrics provided in Figure 4. Although the QRS amplitude in lead II is slightly increased in the CE configuration, the morphology of this lead is only mildly affected $(r=0.91, \mathrm{SD}=0.12)$. Given lead II is traditionally used for detecting rhythm disorders [8], this study indicates that a CE based lead II is reliable for arrhythmia detection.

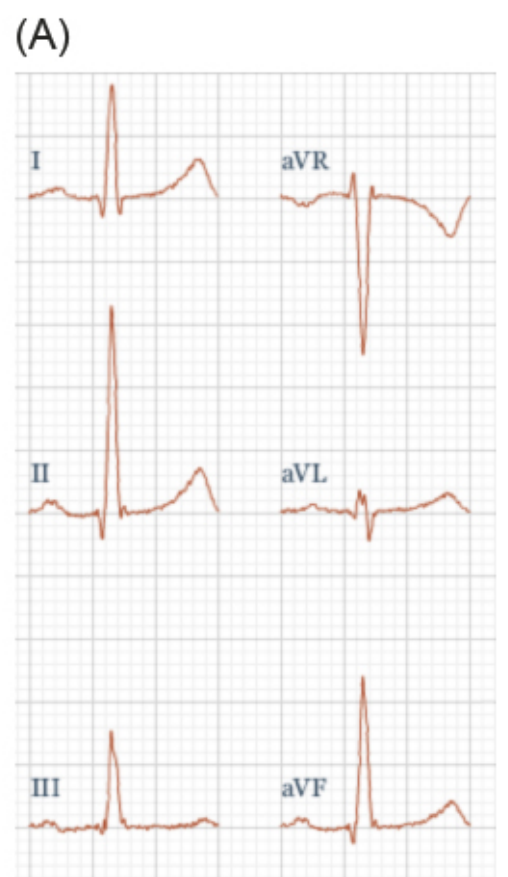

(B)

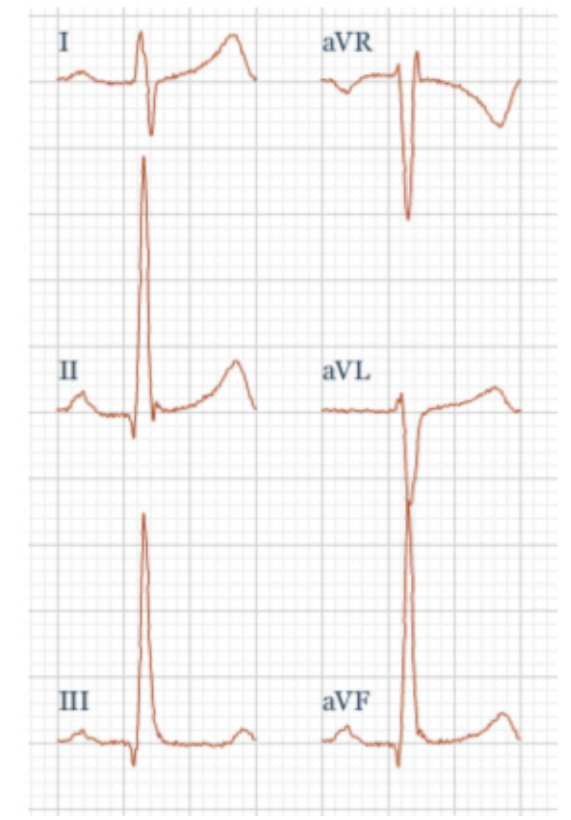

Figure 6 (A) Typical ECG recorded using the ML configuration and (B) the corresponding ECG recorded using the CE configuration (both recorded form the same patient at the same time). This case demonstrates the typical increase in amplitudes in leads III and aVF associated with the CE configuration. A substantial difference in lead aVL is also depicted. 


\section{Limitations}

There are a number of limitations to this study. To control this experiment we compared the ML configuration as per guidelines with one variant of the CE configuration whereas in the real world there would be some variability in electrode placement when using either the ML or the CE configuration. Another limitation is that the 10 cases that were visually inspected by a clinician are not representative since these 10 cases represent cases where the $\mathrm{CE}$ configuration has the most effect on a normal ECG. Therefore a future study will involve recruiting multiple clinicians (to consider inter-rater reliability) to interpret all cases in this study. An additional limitation is that whilst the clinician was blinded as to which ECG was derived from the CE or ML configuration, they could have had a systematic bias given the changes in the cardiac axis in the CE configuration being more rightward.

\section{Conclusions}

Leads aVL, III and aVF are the most contrasting leads when comparing the ML and CE configurations. We confirmed that the CE configuration simulates a slight rightward QRS axis, which can emulate pathologies such as right ventricular hypertrophy and right bundle branch block. However, lead II is reliable when using the CE configuration. Thus the CE approach is suitable for faithfully monitoring the heart's rhythm. Given leads aVL, III and $\mathrm{aVF}$ are not reliable, the CE approach cannot be used for diagnosing pathologies that rely on specific amplitude criteria, that is unless new criteria are designed for the CE configuration. However, the development of new criteria is unrealistic, costly and time-consuming given the current criteria used in today's practice was developed over the last 100 years through a significant amount of trials and data collection. In conclusion, such ECG electrode configurations for the context of $\mathrm{CH}$ [31-33] need to be enhanced to reliably detect CHD. And if these devices include computerized analysis then the results and limitations presented here need to be considered. Future work may include conducting the same study using a larger database of BSPMs (this is possible given there are a large number of heterogeneous 
Page 20

BSPM databases at different research centers around the world [34] - however to date no work has been done to aggregate these datasets).

\section{References}

1. Lutz W, Sanderson W, Scherbov S. The coming acceleration of global population ageing. Nature. 2008;451:716-719.

2. Reynolds L. The future of the NHS--irreversible privatisation? interview by jill mountford. BMJ. 2013;346:f1848.

3. Caulfield BM, Donnelly SC. What is connected health and why will it change your practice? QJM. 2013;106:703-707.

4. De San Miguel K, Smith J, Lewin G. Telehealth remote monitoring for communitydwelling older adults with chronic obstructive pulmonary disease. Telemedicine and e-Health. 2013;19:652-657.

5. Woods LW, Snow SW. The impact of telehealth monitoring on acute care hospitalization rates and emergency department visit rates for patients using home health skilled nursing care. Home Healthc Nurse. 2013;31:39-45.

6. Piotrowicz E, Jasionowska A, Banaszak-Bednarczyk M, Gwilkowska J, Piotrowicz R. ECG telemonitoring during home-based cardiac rehabilitation in heart failure patients. $J$ Telemed Telecare. 2012;18:193-197. 
Page 21

7. Kligfield P, Gettes LS, Bailey JJ, et al. Recommendations for the standardization and interpretation of the electrocardiogram:: Part I: The electrocardiogram and its technology: A scientific statement from the American heart association electrocardiography and arrhythmias committee, council on clinical cardiology; the american college of cardiology foundation; and the heart rhythm society. endorsed by the international society for computerized electrocardiology. Heart Rhythm. 2007;4:394-412.

8. Wagner GS, Marriott HJL. Marriott's Practical Electrocardiography. 11th ed. Philadelphia: Wolters Kluwer Health/Lippincott Williams \& Wilkins; 2008.

9. Barold SS. Norman J.“Jeff” Holter-“Father” of ambulatory ECG monitoring. Journal of Interventional Cardiac Electrophysiology. 2005;14:117-118.

10. Drew BJ, Califf RM, Funk M, et al. Practice standards for electrocardiographic monitoring in hospital settings an american heart association scientific statement from the councils on cardiovascular nursing, clinical cardiology, and cardiovascular disease in the young: Endorsed by the international society of computerized electrocardiology and the american association of critical-care nurses. Circulation. 2004;110:2721-2746.

11. Donnelly N, Harper R, McCAnderson J, et al. Development of a ubiquitous clinical monitoring solution to improve patient safety and outcomes. IEEE; 2012:6068-6073.

12. Jang Y, Noh HW, Lee I, Song Y, Shin S, Lee S. A basic study for patch type ambulatory 3-electrode ECG monitoring system for the analysis of acceleration signal and the limb leads and augmented unipolar limb leads signal. IEEE; 2010:3864-3867.

13. RealTime Technologies. Wearable Wireless Sensor Platform. Available at: http://www.shimmer-research.com. 
Page 22

14. Mason RE, Likar I. A new system of multiple-lead exercise electrocardiography. Am Heart J. 1966;71:196-205.

15. Bond RR, Finlay DD, Nugent CD, Moore G. A web-based tool for processing and visualizing body surface potential maps. $J$ Electrocardiol. 2010;43:560-565.

16. Lux RL, Smith CR, Wyatt RF, Abildskov JA. Limited lead selection for estimation of body surface potential maps in electrocardiography. IEEE Transactions on Biomedical Engineering. 1978;25:270-276.

17. Bond RR, Finlay DD, Nugent CD, Moore G, Guldenring D. A simulation tool for visualizing and studying the effects of electrode misplacement on the 12-lead electrocardiogram. J Electrocardiol. 2011;44:439-444.

18. Kania M, Rix H, Fereniec M, et al. The effect of precordial lead displacement on ECG morphology. Med Biol Eng Comput. 2014;52:109-119.

19. Finlay DD, Nugent CD, Nelwan SP, Bond RR, Donnelly MP, Guldenring D. Effects of electrode placement errors in the EASI-derived 12-lead electrocardiogram. $J$ Electrocardiol. 2010;43:606-611.

20. Schijvenaars BJ, Kors JA, van Herpen G, Kornreich F, Van Bemmel J. Interpolation of body surface potential maps. J Electrocardiol. 1995;28:104-109.

21. Bond RR, Finlay D, Nugent C, Breen C, Guldenring D, Daly M. The effects of electrode misplacement on clinicians' interpretation of the standard 12-lead electrocardiogram. Eur J Intern Med. 2012;23:610-615. 
Page 23

22. Bond RR, Finlay DD, Nugent CD, Moore G, Guldenring D. A usability evaluation of medical software at an expert conference setting. Comput Methods Programs Biomed. 2014;113:383-395.

23. Bond RR. Electrode Misplacement Simulator. Available at: http://scm.ulster.ac.uk/ scmresearch/bond/ems/.

24. Drew B. Standardization of electrode placement for continuous patient monitoring: Introduction of an assessment tool to compare proposed electrocardiogram lead configurations. J Electrocardiol. 2011;44:115-118.

25. Wagner GS, Marriott HJL. Marriott's Practical Electrocardiography. 11th ed. Philadelphia: Wolters Kluwer Lippincott Williams \& Wilkins; 2008.

26. Hoseini S, Moeeny A, Shoar S, et al. Designing nomogram for determining the hearts QRS axis. Journal of Clinical and Basic Cardiology. 2012;14:12-15.

27. Gari. Clifford G.D., Azuaje, F., McSharry P.E. (Eds): Advanced Methods and Tools for ECG Analysis. Artech House Publishing, October 2006.

28. Bond RR. ECGs selected for serial comparison. Available at: http://scm.ulster.ac.uk/ scmresearch/bond/clincal_analysis_final.pdf

29. Goldberger AL. Clinical Electrocardiography:A Simplified Approach. 5th ed. London: Mosby; 1994.

30. Hampton JR. The ECG made Easy. 6th ed. Edinburgh ; New York: Churchill Livingstone; 2003. 
Page 24

31. Angius G, Pani D, Raffo L, Randaccio P, Seruis S. A tele-home care system exploiting the DVB-T technology and MHP. Methods Inf Med. 2008;47:223-228.

32. Bidargaddi N, Sarela A. Activity and heart rate-based measures for outpatient cardiac rehabilitation. Methods Inf Med. 2008;47:208-216.

33. Spyropoulos B, Tzavaras A, Botsivaly M, Koutsourakis K. Ensuring the continuity of care of cardiorespiratory diseases at home. Methods Inf Med. 2010;49:156-160.

34. Hoekema R, Uijen GJH, Van Oosterom A, "On selecting a body surface mapping procedure," J Electrocardiol., vol. 32, pp. 93-101, April, 1999. 
Page 25

Page 25 
Page 26

Page 26 